\title{
Теневой банковский сектор при регулировании капитала и режиме ПВР ${ }^{1}$
}

\section{Мария Ермолова*}

Национальный исследовательский университет «Высшая школа экономики», Москва, Россия

\section{Информация о статье}

Поступила в редакциюю:

09.12 .2020

Принята

к опубликованию:

21.12.2020

УДК 336

JEL G21, G28

\section{Ключевые слова:}

теневой банковский сектор, регулирование капитала, подход на основе внутренних рейтингов (ПВР), благосостояние общества, потери вкладчиков

\section{Keywords:}

shadow banking, capital regulation, internal ratings-based approach (IRB), the welfare of society, losses of investors

\begin{abstract}
Аннотация
$B$ исследовании предложена модификачия модели 1 G. Ordoñez [1]. В [1] предполагалось, что асимметрия информации в банковском секторе приводит к ограничительной политике, при которой регулятор запрещает вложения в рисковые активы. В статье показывается, что данная предпосылка не реалистична, так как на практике регулятор обладает большим набором инструментов, например, может внедрить подход на основе внутренних рейтингов (далее - ПВР), который обеспечивает детальную оченку риска. Продемонстрировано достижение оптимального состояния рынка при более реалистичной предпосылке. В модель также внедрено регулирование капитала. Показано влияние норматива достаточности капитала на размер теневого банкинга.
\end{abstract}

\section{Shadow Banking Under Capital Regulation and IRB Approach $^{* *}$}

Maria Ermolova

\section{Abstract}

The article discusses the mechanism of risk-shifting in the presence of information asymmetry. The model is based on [1]. Due to the asymmetry of information, the regulator cannot differentiate bank assets by the risk level, and therefore cannot guarantee (in particular, to investors) an adequate risk level of banks such that is sufficient to cover losses by capital in the event of stress. As a result, the regulator designs a policy that prohibits investments in any risky assets. This leads to the fact that banks transfer their activities outside the control of the regulator. It is defined as shadow banking.

Information asymmetry leads to not optimal decisions. In particular, banks cannot invest in superior assets, despite the fact that these assets generally have an acceptable risk level. [1] proposed reducing the problem of asymmetry by maintaining subsidies, in which banks in shadow banking must pay fees for

\footnotetext{
${ }^{1}$ Автор выражает благодарность Г.И. Пеникасу за знакомство со статьей (Ordoñez 2018) и обсуждение на протяжении всех этапов работы. Автор благодарит Ф.Т. Алескерова и Д. А. Веселова за полезные комментарии, полученные на семинаре Международного центра анализа и выбора решений 17 мая 2020. Автор выражает благодарность анонимному рецензенту за содержательное обсуждение работы.

Статья подготовлена в рамках Программы фундаментальных исследований Национального исследовательского университета "Высшая школа экономики" (НИУ ВШЭ) с использованием программы государственной субсидии "5-100" для ведущих вузов Российской Федерации.

* DOI: https://dx.doi.org/10.24866/2311-2271/2020-4/113-128

*** Expressed opinions are solely those of the author and not necessarily that of the affiliated institutions. Author acknowledges Henry Penikas for introducing to the article (Ordoñez, 2018) and discussing throughout all stages of the work. Author acknowledges Fuad Aleskerov and Dmitry Veselov for the useful comments received at the Workshop by the International Centre of Decision
} 
their choice to operate outside of regulation.

This article suggests another method for reducing the volume of shadow banking. This method involves the introduction of IRB, namely a differentiated calculation of the risk level for each asset individually based on internal models of banks that meet the requirements of the regulator. Due to a more differentiated risk assessment, constant validation of models and detailed reporting, the regulator will be able to control investments in superior assets and thereby reduce banks' entry into shadow banking.

The paper notes the impact of the capital requirements on the volume of shadow banking. The modification of the model [1] by adding IRB mode and introducing banks' calculation and compliance with capital requirements allowed to find the boundary levels of the capital adequacy ratio at which banks charge their strategy in favour of shadow banking.

\section{Введение}

Ежегодно Совет по финансовой стабильности (далее - СФС), созданный странами G20, публикует отчет, в котором оценивает размер «теневого банкинга» («Shadow Banking»). В узком определении СФС теневой банкинг представляет собой совокупность некредитных финансовых организаций, выполняющих роль кредитного посредника, но находящихся вне рамках банковского регулирования. На конец 2018 г. объем теневого банкинга составил 51 трлн долларов США [2] или 60\% от объема мирового ВВП (86 трлн долларов США $)^{2}$. Значительный размер теневого банкинга и неприменение к нему регулирования говорит о его существенном влиянии на финансовую стабильность системы.

В 2018 г. теневому банкингу была посвящена статья [1] в журнале «American Economic Journal: Macroeconomics». В [1] отмечается, что кредитное посредничество, находящееся вне общего банковского регулирования (теневой банкинг), увеличивает уровень благосостояния общества, когда он идет в дополнение к регулируемой банковской системе (традиционный банкинг). Однако при этом все еще не достигается наивысшего возможного уровня благосостояния ввиду наличия асимметрии информации. Асимметрия информация приводит к неоптимальным решениям. Регулятор запрещает банкам вкладываться в любые рисковые активы, так как ввиду отсутствия достаточной информации не может среди рисковых активов выделить высокорискованные вложения. Это побуждает банки переходить в теневой банкинг, где вложения в рисковые активы доступны из-за отсутствия регулирования. Инвесторы не умеют оценивать риск активов, поэтому требуют повышенную ставку процента за вложения в теневом банкинге. В результате банки недополучают прибыль, а инвесторы несут повышенный риск. G. Ordoñez [1] предлагает внедрить такой механизм, при котором банки, решившие перейти в теневой банкинг платят взносы, которые идут банкам из традиционного сектора в качестве субсидии. Однако, как сам отмечает G. Ordoñez [1], данный механизм сложен для реализации на практике.

В настоящей работе в качестве решения, позволяющего снизить асимметрию информации и объем теневого банкинга, предлагается внедрение ПВР. На текущий момент ПВР уже применяют более 2000 банков в мире и 2 банка в России. ПВР подход, в отличие от 5 возможных градаций риска в стандартизированном подходе, позволяет более детально дифференцировать риск и транслировать его как регулятору, так и рынку через отчетность благодаря индивидуальной оценке риска активов на основе внутренних моделей банка, более чувствительных к изменениям состояний экономики. В статье помимо ПВР подхода в модель [1] добавлено регулирование капитала и показано, что от выбора значения норматива достаточности капитала значительно зависит объем теневого банкинга. В качестве результата рассчитаны границы нормативов достаточности капитала (CAR), превышение которых может увеличивать вероятность перехода банков в теневой банкинг.

${ }^{2}$ URL: https://data.worldbank.org/indicator/NY.GDP.MKTP.CD?view=chart 


\section{Обзор литературы}

В модели [1] существуют 3 типа активов (безрисковые, низкорискованные и высокорискованные) и 3 агента (инвесторы, регулятор и банки). Уровень осведомленности о риске актива растет от инвестора к банкам. В результате на традиционном банкинге регулятор запрещает вложения в любые рисковые активы, а на теневом - инвесторы требуют повышенную ставку процента. Банк решает, в каком типе банкинга остаться, сравнивая прибыли в традиционном и теневом банкинге, учитывая также наличие доступа к активам с низким уровнем риска (их количество ограничено).

В модели [1] есть 2 спорные предпосылки, которые будут рассмотрены далее. Во-первых, в модели [1] не учитывается ограничение на капитал, которое влияет на выбор портфеля активов банками и выбор типа банковской системы, на котором осуществлять кредитование. С одной стороны, высокие требования сподвигнут больше банков переходить в теневой банкинг. С другой стороны, за счет требований к капиталу размер потерь в традиционном банкинге меньше. Оба момента влияют на объем теневого банкинга. Вопрос влияния требований к капиталу и размеров теневой банковской системы остается актуальным. Исследователи не пришли к однозначному выводу о том, требуется повышать или снижать требования к капиталу, чтобы повысить финансовую стабильность [3]. В работе [4] отмечено, что регулирование влияет на стратегию банков (объем активов и их уровень риска) и их решение выйти на теневой банкинг с внебалансовым кредитованием. Авторы замечают, что чем выше уровень капитала банка, тем выше вероятность, что он уйдет на теневой банкинг. G. Buchak, G. Matvos, T. Piskorski, A. Seru [5], наоборот, показывают, что ужесточение требований к капиталу помогают бороться с излишним принятием на себя риска. Однако по их расчетам благосостояние общества повышает не фиксированные требования к капиталу, а динамические (эндогенные). Текущая работа поможет привести дополнительные аргументы в пользу мнения, что требования к капиталу не могут быть завышены, так как при достижении определенной границы ведут к увеличению теневой системы.

Во-вторых, [1] приуменьшает роль и возможности регулятора оценивать риск банков и системы в целом. Например, регулятор может оценить риск активов банков через внедрение продвинутых подходов к оценке риска (ПВР). Режим ПВР обязывает банки использовать продвинутые подходы к оценке риска и раскрывать в отчетности уровень принятого риска, его оценки и сравнение с фактическими реализованными потерями. ${ }^{3}$

\section{Скорректированная модель (Ordoñez, 2018)}

Добавление норматива достаточности капитала. Рассмотрим первую модицификацию модели [1] - учет регулирования капитала через норматив. Банки должны обладать достаточным количеством капитала, чтобы быть способными покрыть непредвиденные потери. Для этого регулятор вводит минимальное значение норматива достаточности капитала (Capital Adequacy Ratio CAR). В соглашениях Базель II [6] и Базель III [7] $\overline{C A R}=8 \%$. От Банка требуется выполнение следующего условия:

$$
\frac{k}{\sum_{i} R W_{i}^{*} A_{i}} \geq \overline{C A R}
$$

где і - порядковый номер актива;

$\overline{C A R}$ - минимальное значение норматива достаточности капитала;

${ }^{3}$ См. Указание Банка России от 12.05.2020 № 5456-У 
$\mathrm{k}$ - размер капитала банка;

$R W_{i}$ - коэффициент риска актива;

$A_{i}$ - стоимость актива.

Введение CAR повлияет на выбор банка объема и риска вложений. При увеличении CAR банк будет либо понижать объем вложений $\left(A_{i}\right)$, либо переходить к менее рискованным активам (с более низким $R W_{i}$ ). Поскольку ожидаемая доходность низкорисковых активов (LR, low risk) выше чем у безрисковых активов (NR, no risk), банки будут выбирать первую стратегию - понижать объем вложений.

Добавление режима ПВР. Рассмотрим вторую модицификацию модели [1] - учет режима ПВР. Банки имеют две опции расчета коэффициента риска $R W_{i}$ : стандартизированный подход и ПВР. При стандартизированном подходе банк полагается на оценки $R W_{i}$ регулятора, при ПВР - на оценки собственных моделей. В стандартизированном подходе одинаковый $R W_{i}$ применяется для всех активов, попадающих в одну группу активов по определенному признаку (см. раздел «Standardised Approach for Credit Risk» (BCBS-d424 December 2017)). ПВР является более чувствительным к риску. Даже в рамках одной группы есть дифференция риска. Банки, использующие ПВР, показывают распределение вложений по уровню риска, в отчетности регулятору. Таким образом, регулятор видит дифференцированный разрез уровня риска банков.

Внедрение ПВР моделей регулятором дает возможность ему надзирать за уровнем риска активов, а следовательно, различать активы с низким и высоким уровнем риска. Это позволяет регулятору вести менее ограничительную политику. Регулятор все еще запрещает инвестировать в активы с высоким уровнем риска, но отменяет запрет на вложения в активы с низким уровнем риска в традиционном секторе. Одновременно регулятор требует соблюдения CAR.

Обе модификации модели (CAR и ПВР) расширяют возможности инвестирования за счет снятия запрета на вложения в низкорисковые активы, с другой стороны, ограничивает вложения через норматив. В этом случае банк будет решать следующую задачу. Если к активам с низким уровнем риска есть доступ, то банк решает, в каком банкинге (традиционном или теневом) инвестировать в низкорискованные активы. Иначе, при отсутствии доступа, банк решает, вкладываться в безрисковые активы в традиционном банкинге или в высокорискованные активы в теневом банкинге.

О формировании инвесторами ставки процента. Обсудим, как внедрение режима ПВР и снятие запрета на вложения в LR в традиционном банкинге может повлиять на формирование инвесторами ставки процента за предоставления инвестиций.

B активы с низким уровнем риска (LR активы) в традиционном банкинге могут вложиться только банки, применяющие ПВР. Для инвесторов такие банки идентифицируются наличием официального публичного разрешения регулятора на право применения ПВР, которое выдается банку после регуляторной валидации. Ставка для ПВР банков будет обратно пропорциональна доле инвестиций за вычетом ожидаемых потерь по ним.

$$
R_{T B-L R}=\frac{1}{1-E L_{L R}}
$$

Для остальных типов активов возможно рассмотреть два варианта формирования ставок, как представлено в табл. 1.

Отметим, что вариант 2 лучше отражает низкую осведомлённость инвестора о вложениях банков. Вложения в низкорисковые активы в традиционном 
банкинге инвестор может распознать через список банков, получивших на это разрешение от регулятора (при использовании ПВР). Уровень риска остальных вложений банков для инвестора не различимы.

Таблий 1

Методы формирования ставок инвесторов

\begin{tabular}{|c|c|c|c|}
\hline Банкинг & Актив & Вариант 1 & Вариант 2 \\
\hline \multirow{2}{*}{ TB } & $\mathrm{LR}$ & $R_{T B-L R}$ & $R_{T B-L R}$ \\
\cline { 1 - 3 } & $\mathrm{NR}$ & $R_{T B-N R}$ & \multirow{2}{*}{$R_{\text {rest }}$} \\
\hline \multirow{2}{*}{$\mathrm{SB}$} & $\mathrm{LR}$ & \multirow{2}{*}{$R_{S B}$} & \\
\cline { 1 - 2 } & $\mathrm{HR}$ & & \\
\hline
\end{tabular}

Примечание: вариант 1 ближе к методу формирования ставок в [1]. Поскольку ожидаемые потери по безрисковым и низкорискованным активам в [1] одинаковы, то $\mathrm{R}_{\mathrm{TB}-\mathrm{LR}}=\mathrm{R}_{\mathrm{TB}-\mathrm{NR}}$.

Источник: составлено автором

Вариант 1 формирования ставок инвесторами. Ставка для безрисковых активов в традиционном банкинге будет определяться по тому же принципу, что и для низкорисковых активов. При более высокой доходности активов с низким уровнем риска ПВР банки будут всегда предпочитать их безрисковым вложениям. Поэтому, все банки, кто не имеет разрешения на применение ПВР в рамках традиционного сектора, могут вкладываться только в безрисковые активы. Это позволит инвесторам их идентифицировать.

$$
R_{T B-N R}=\frac{1}{1-E L_{N R}}
$$

Из-за отсутствия возможности различать уровень риска банков в теневом банкинге инвестор будет назначать им общую ставку, которая будет рассчитываться из распределения вложений по уровню риска.

$$
R_{S B}=\frac{1}{\left(1-E L_{N R}\right) x_{S B-H R}+\left(1-E L_{S B-L R}\right) x_{S B-L R}},
$$

где $x_{S B-L R}$ - доля вложений в низкорискованные активы в теневом банкинге.

Вариант 2 формирования ставок инвесторами. В случае если инвесторы распознают только между ПВР и не ПВР- банками, то ставка процента для всех активов кроме низкорискованных будет рассчитываться следующим образом.

$$
R_{\text {rest }}=\frac{1}{\left(1-E L_{H R}\right) x_{S B-H R}+\left(1-E L_{S B-L R}\right) x_{S B-L R}+\left(1-E L_{T B-N R}\right) x_{T B-N R}}
$$

Поскольку $E L_{H R}>E L_{L R}>E L_{N R}$, то при переходе от менее к более рискованным активам, ставка будет повышаться.

\section{Выбор между вложением в безрисковые активы в традиционном банкинге или в высокорискованные активы в теневом банкинге}

Норматив достаточности капитала, который был внедрен по сравнению с [1], ограничивает вложения в традиционном банкинге. CAR для NR активов рассчитывается как:

где

$$
\begin{aligned}
& \frac{k}{R W_{N R} A_{N R}} \geq C A R \\
& A_{N R}=\gamma_{N R}(\operatorname{Inv}+k)
\end{aligned}
$$


Отметим, что в RW уже заложен вычет EL, поэтому RW определяет только непредвиденные потери.

Подставим (7) в (6) и вычислим максимально возможный объем инвестиций в безрисковые активы при соблюдении норматива достаточности капитала в традиционном банкинге $\overline{\gamma_{N R}}$ :

$$
\begin{aligned}
& \frac{k}{(\operatorname{Inv}+k) R W_{N R} \gamma_{N R}} \geq C A R \\
& \overline{\gamma_{N R}}=\frac{k}{\operatorname{CAR}(\operatorname{Inv}+k) R W_{N R}}
\end{aligned}
$$

Поскольку в теневом секторе регулирование не соблюдается, то доля $\mathrm{HR}$ активов ограничиваться нормативом не будет.

Если банк вложиться в безрисковые активы в традиционном банкинге, то его прибыль будет:

$$
\pi_{T B-N R}=\left(1-E L_{N R}\right) \overline{\gamma_{N R}}(\operatorname{Inv}+k) R_{N R}^{L}-\left(1-E L_{N R}\right) \overline{\gamma_{N R}} \operatorname{Inv} R_{T B-N R}-\overline{\gamma_{N R}} k
$$

Если банк вложиться в высокорискованные активы в теневом банкинге, то его прибыль будет:

$$
\pi_{S B-H R}=\left(1-E L_{H R}\right)(I n v+k) R_{H R}^{L}-\left(1-E L_{H R}\right) I n v R_{S B-H R}-k
$$

Разница в выручке двух случаев (первое слагаемое в формуле) в терминах (Ordoñez 2018) будет соответствовать издержкам теневого банкинга:

$$
C_{S B}=(I n v+k)\left(\left(1-E L_{N R}\right) \overline{\gamma_{N R}} R_{N R}^{L}-\left(1-E L_{H R}\right) R_{H R}^{L}\right)
$$

Разница в выплатах инвестору будет представлять выгоду от теневого банкинга:

$$
B_{S B}=\operatorname{Inv}\left(\left(1-E L_{N R}\right) \overline{\gamma_{N R}} R_{T B-N R}-\left(1-E L_{i n f}\right) R_{S B-H R}\right)-k\left(\overline{\gamma_{N R}}+1\right)
$$

Равенство издержек и выгоды определит оптимальный уровень участия банков в теневом банкинге при вложении в высокорискованные активы.

Если ставка инвесторами формируется по варианту 1 , то $R_{T B-N R}$ определяется ожидаемыми потерями, а $R_{S B-H R}$ зависит от выбора банков, в каком типе банкинга и в каком объеме вкладываться в LR активы. Зная последнее, получаем уравнение с одной переменной $x_{S B-H R}$.

Если ставка инвесторами формируется по варианту 2 , то $R_{T B-N R}=R_{S B-H R}=$ $R_{\text {rest }}$. $R_{\text {rest }}$ зависит фактически от трех переменных $x_{S B-H R}$ и $x_{S B-L R}$, т.к. $x_{T B-N R}=$ $1-\alpha-x_{S B-H R}$.

Поскольку мы увидели, что выбор между инвестициями в NR или HR активы зависит от выбора объемов и типа банкинга для инвестирования в LR активы, рассмотрим, как этот выбор делается.

\section{Выбор между традиционным и теневым банкингом для вложений в низкорискованные активы}

Регулирование капитала, как и в случае с NR активами будет ограничивать количество инвестиций, который банк может сделать в низкорисковые активы в традиционном банкинге. 
где

$$
\begin{aligned}
\frac{k}{R W_{L R} A_{L R}} & \geq C A R \\
A_{L R} & =\gamma_{L R}(\operatorname{Inv}+k)
\end{aligned}
$$

Подставим (15) в (14):

$$
\frac{k}{(I n v+k) R W_{L R} \gamma_{L R}} \geq C A R
$$

Выразим предельно допустимый уровень вложений в низкорискованные активы с учетом норматива:

$$
\overline{\gamma_{L R}}=\frac{k}{C A R(\operatorname{Inv}+k) R W_{L R}}
$$

Сравним прибыли от вложений в низкорискованные активы в традиционном и теневом банкинге:

$$
\begin{gathered}
\pi_{T B}\left(r_{L R}\right)=\left(1-E L_{L R}\right) \overline{\gamma_{L R}}(\operatorname{Inv}+k) R_{L R}^{L}-\left(1-E L_{L R}\right) \overline{\gamma_{L R}} \operatorname{Inv} R_{T B-L R}-\overline{\gamma_{L R}} k \\
\pi_{S B}\left(r_{L R}\right)=\left(1-E L_{L R}\right) \alpha(\operatorname{Inv}+k) R_{L R}^{L}-\left(1-E L_{L R}\right) \alpha \operatorname{Inv} R_{S B}-\alpha k
\end{gathered}
$$

Объем вложений в традиционном банкинге ограничен $\overline{\gamma_{L R}}$. Если $\overline{\gamma_{L R}}<\alpha$, то в теневом банкинге можно получить выручку выше на $\left(1-E L_{L R}\right)(\operatorname{Inv}+$ $k) R_{L R}^{L}\left(\alpha-\overline{\gamma_{L R}}\right)$. Разницы в выручке не будет, если $\overline{\gamma_{L R}}=\alpha$. Это возможно при $C A R=\frac{k}{\alpha(I n v+k) R W_{L R}}$. Значения CAR ниже данного порога будем называть низким уровнем CAR.

На разницу прибылей в традиционном и теневом банкинге может также влиять разрыв в издержках. Издержки в теневом банкинге возрастут с ростом вложений в высокорискованные активы. Если в теневом банкинге отсутствуют банки с вложениями в высокорискованные активы, то ставка для низкорискованных активов в теневом и традиционном банкинге одинакова.

В терминах [1] рассчитаем издержки и выгоды от теневого банкинга при выборе между вложениями в LR активы в традиционном или теневом банкинге. Под издержками теневого банкинга понимается разница между выручкой в традиционном и теневом банкинге. Ранее определили, что издержки будут равны:

$$
C_{S B-L R}=\left(1-E L_{L R}\right)(\operatorname{Inv}+k) R_{L R}^{L}\left(\alpha-\overline{\gamma_{L R}}\right)
$$

Под выгодой теневого банкинга понимается разница между издержками банка в традиционном и теневом банкинге.

$$
B_{S B-L R}=\left(1-E L_{L R}\right) \operatorname{Inv}\left(\overline{\gamma_{L R}} R_{T B-L R}-\alpha R_{S B-L R}\right)+\left(\alpha-\overline{\gamma_{L R}}\right) k
$$

Вариант 1 формирования ставок инвестора. Ставки в традиционном и теневом банкинге будут равны только в случае, если ни один из банков не вложиться в HR активы.

$$
R_{T B-L R}=R_{S B-L R}=\frac{1}{1-E L_{L R}}
$$

при $x_{S B-H R}=0$ (см. формулу (4)).

При ненулевом вложении в HR активы, ставка в теневом банкинге становится выше ставки в традиционном банкинге. Издержки от вложения в LR активы в теневом банкинге становятся выше, чем в традиционном банкинге. 
Найдем предельный уровень участия банков во вложениях в HR активах, при котором участие в традиционном банкинге в LR активе все еще выгоднее участия в теневом банкинге в LR активах. Для этого приравняем выражения (20) и (21), подставим выражения (2), (4) и (17).

$$
\begin{aligned}
& \overline{x_{S B-H R}} \\
& =\frac{\left(1-E L_{L R}\right)\left(-I n v+k+(I n v+k)\left(-1+E L_{L R}\right) R_{L R}\right)(-k+C A R(I n v}{\left(E L_{H R}-E L_{L R}\right)\left((\operatorname{Inv}+k)\left(-1+E L_{L R}\right) R_{L R}\left(-k+C A R(\operatorname{Inv}+k) \alpha R W_{L R}\right)+k(\operatorname{Inv}-i\right.}
\end{aligned}
$$

При $x_{S B-H R}>\overline{x_{S B-H R}}$, ставка инвестора в теневом банкинге настолько высока, что не покрывает выгоды от отсутствия ограничения на вложения из-за норматива. Таким образом, при $x_{S B-H R}>\overline{x_{S B-H R}}$ традиционный банкинг с регулированием будет предпочтительней теневого банкинга без регулирования.

На рис. 1 показано, что уровень прибыли в традиционном секторе не зависит от доли вложения в HR активы (при формировании ставки инвесторами по варианту 1), но будет снижаться при увеличении норматива CAR. Уровень прибыль в теневом секторе снижается с ростом доли в LR в традиционном банкинге. В этом случаев инвестор видит, что теневой сектор в большей степени заполняется HR активами и повышает уровень ставок.

Рис. 1 представляет собой срез для одного среза норматива CAR (CAR = $10 \%$ ). Из рис. 1 следует, что существует такой норматив достаточности капитала, при котором пунктирная линия пересечется со сплошной линией. Изменение соотношение прибылей на традиционном и теневом секторе в зависимости от CAR можно увидеть на рис. 2. При заданных параметрах установление норматива свыше $46 \%$ приведет к переходу банков из традиционного в теневой банкинг.

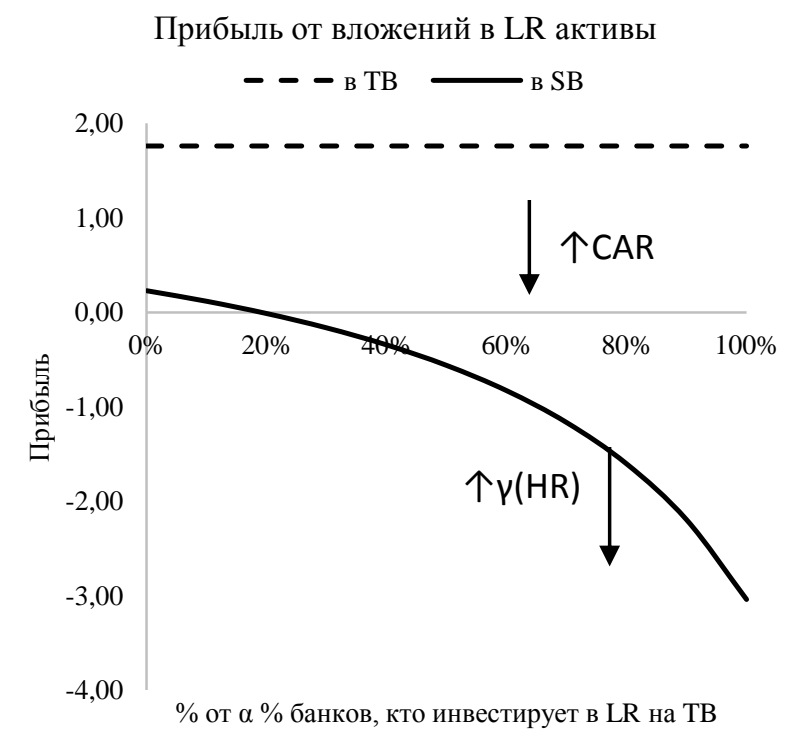

Puc. 1. Сравнение прибыли от вложений в низкорискованные активы (LR) в традиционном

(TB) и теневом (SB) банкинге в зависимости от доли вложений в LR на TB

Параметры для графика: $\gamma(\mathrm{LR}-\mathrm{TB})=100 \% ; \gamma(\mathrm{HR}-\mathrm{SB})=50 \%$; $\mathrm{CAR}=10 \%, \alpha=40 \%$, R(NR-TB $)=$ $1.3, \mathrm{R}(\mathrm{LR}-\mathrm{TB})=1.5, \mathrm{R}(\mathrm{HR}-\mathrm{SB})=2.0$, использовался вариант 1 формирования ставок инвесторами

Источник: составлено автором 
Прибыль от вложений в LR активы

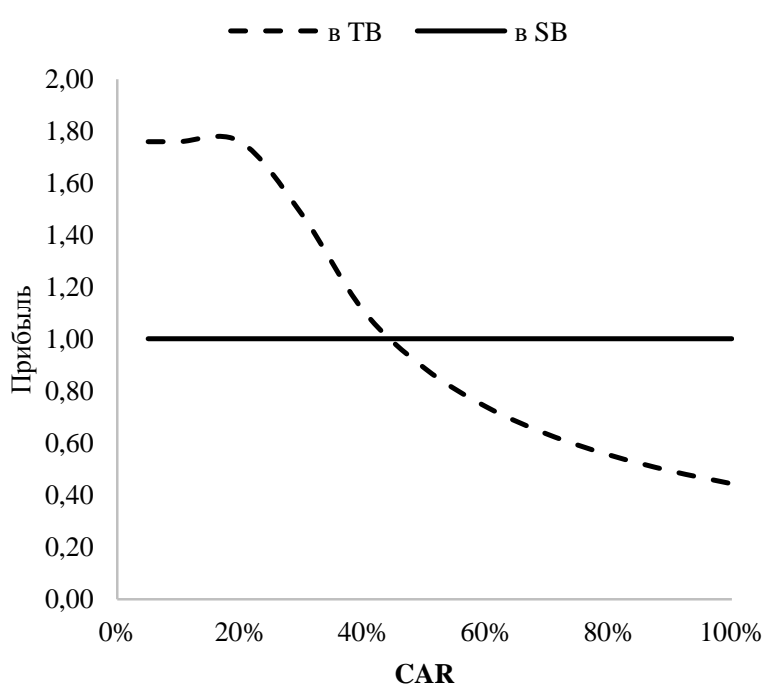

Puc. 2. Сравнение прибыли от вложений в низкорискованные активы (LR) в традиционном (TB) и теневом (SB) банкинге в зависимости от CAR Параметры для графика: $\gamma(\mathrm{LR}-\mathrm{TB})=50 \% ; \gamma(\mathrm{HR}-\mathrm{SB})=10 \% ; \alpha=40 \%$; $(\mathrm{NR}-\mathrm{TB})=1.3, \mathrm{R}(\mathrm{LR}-\mathrm{TB})=$ $1.5, \mathrm{R}(\mathrm{HR}-\mathrm{SB})=2.0$

Источник: составлено автором

Вариант 2 формирования ставок инвестора. В отсутствии вложений в $\mathrm{HR}$ в теневом банкинге $R_{\text {rest }}$ может оказаться меньше $R_{L R-T B}$ за счет того, что в $R_{\text {rest }}$ включается ценообразование по безрисковым активам. В этом случае прибыль от вложений в LR риски на SB всегда выше. Более того, разрыв между прибылью на SB и TB увеличивается с ростом CAR.

Прибыль от вложений в LR активы

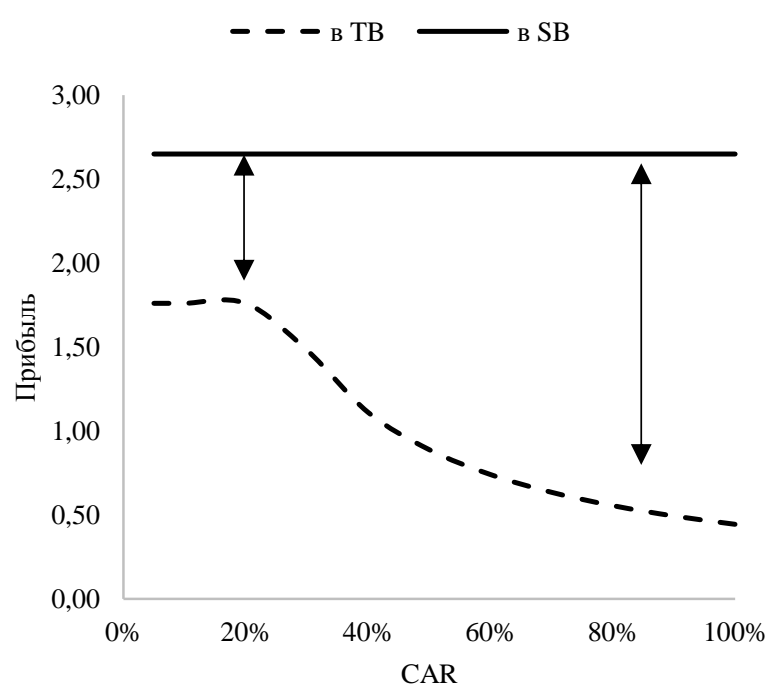

Puc. 3. Разрыв прибыли на SB и TB от вложений в LR при формировании ставки по методу 2 (в отсутствие вложений в HR на SB)

Параметры для графика: $\gamma(\mathrm{LR}-\mathrm{TB})=100 \% ; \gamma(\mathrm{HR}-\mathrm{SB})=0 \% ; \alpha=40 \%, \mathrm{R}(\mathrm{NR}-\mathrm{TB})=1.3$, $\mathrm{R}(\mathrm{LR}-\mathrm{TB})=1.5, \mathrm{R}(\mathrm{HR}-\mathrm{SB})=2.0$, метод 2 формирования ставки инвесторами.

Источник: составлено автором 
Однако с увеличением доли вложений в HR активы, ставка $R_{\text {rest }}$ увеличивается. Найдем предельный уровень вложений в HR, при котором вкладываться в LR риски будет выгоднее на TB по сравнению с SB. Для этого приравняем выражения (20) и (21), подставим выражения (2), (5) и (17).

$\overline{x_{S B-H R}}$
$=\frac{C A R \operatorname{Inv}(\operatorname{Inv}+k) \alpha\left(-1+E L_{L R}\right) R V}{\left(-1+E L_{H R}\right)\left((\operatorname{Inv}-k) k+(\operatorname{Inv}+k)\left(-1+E L_{L R}\right) R_{L R}\left(-k+C A R(\operatorname{Inv}+k) \alpha R W_{L R}\right)-C A R\right.}$

При $x_{S B-H R}>\overline{x_{S B-H R}}$, ставка инвестора $R_{\text {rest }}$ настолько высока, что не покрывает выгоды от отсутствия ограничения на вложения из-за норматива. Таким образом, при $x_{S B-H R}>\overline{x_{S B-H R}}$ традиционный банкинг с регулированием будет предпочтительней теневого банкинга без регулирования для вложений в LR.

\section{Вычет потерь вкладчиков из благосостояния}

Одним из спорных моментов в модели [1] является неучет потерь вкладчиков в расчете благосостояния общества. Далее показано, что вывод о положительном влиянии теневого банкинга может быть опровергнут, если в расчет благосостояния включать потери вкладчиков. На рис. 4 показано, что из-за более высокого уровня потерь в теневом банкинге из-за вложений в HR активы потери вкладчиков выше, чем в традиционном банкинге, что снижает полезность теневого банкинга.

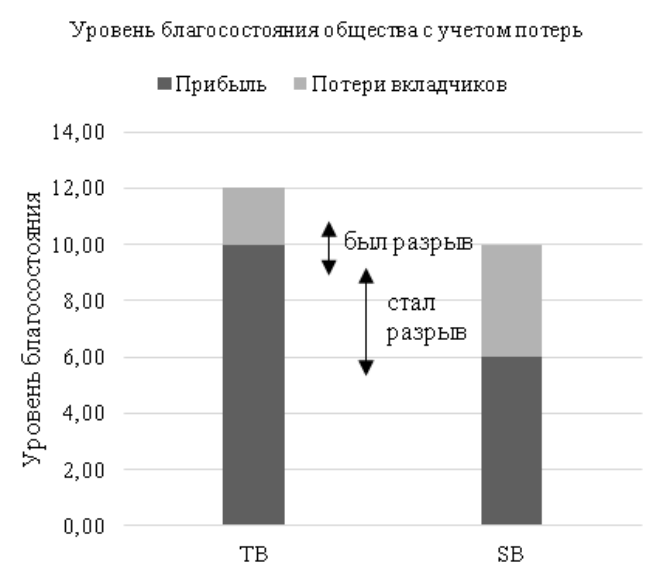

Рис. 4. Объяснение влияния потерь инвесторов на расчет благосостояния Источник: составлено автором

На рис. 5 видна существенная разница потерь инвесторов при вложениях в HR активы или в NR и LR активы.

На рис. 6 на первом графике показан расчет благосостояния для LR активов, на втором графике - для HR активов. Если сравнить линию с круглым маркером, то благосостояние в размере прибыли от вложений в HR активы выше. Однако если мы учтем потери вкладчиков, то соотношение прибылей для LR и $\mathrm{HR}$ активов изменится. Мы видим, что потери вкладчиков от вложений в HR активы сильно больше, что создает такой значимый разрыв между линиями на втором графике. 


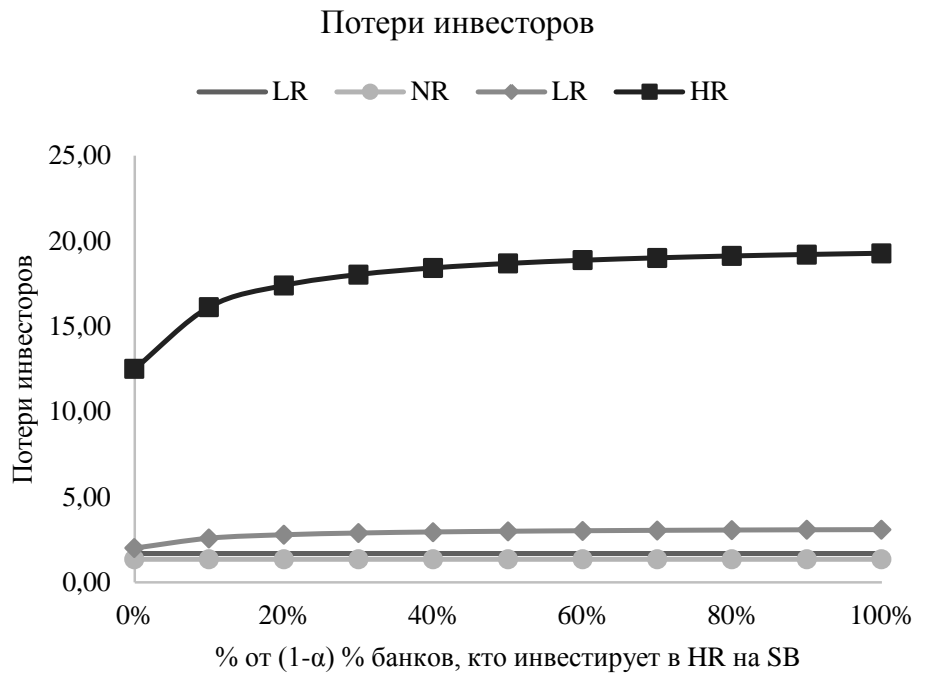

Рис. 5. Потери инвесторов от участия банков во вложениях при двух видах банкинга Параметры для графика: $\gamma(\mathrm{LR}-\mathrm{TB})=90 \% ; \gamma(\mathrm{HR}-\mathrm{SB})=50 \%$; $\mathrm{CAR}=30 \%, \alpha=40 \%, \mathrm{R}(\mathrm{NR}-\mathrm{TB})=1.3$, $\mathrm{R}(\mathrm{LR}-\mathrm{TB})=1.5, \mathrm{R}(\mathrm{HR}-\mathrm{SB})=2.0$

Источник: составлено автором

\section{Сравнение прибыли в традиционном и теневом банкинге}

Внедрив три модификации в модель (регулирования капитала, режим ПВР и расчет благосостояния с учетом потерь), рассмотрим, как изменяются выводы о положительном влиянии теневого банкинга на благосостояние общества.

Пусть к LR акивам имеют доступ только 40\% банков. У каждого банка имеется капитал в размере 2 ед. и инвестиции в размере 20 ед. Иные характеристики представлены в табл. 2.
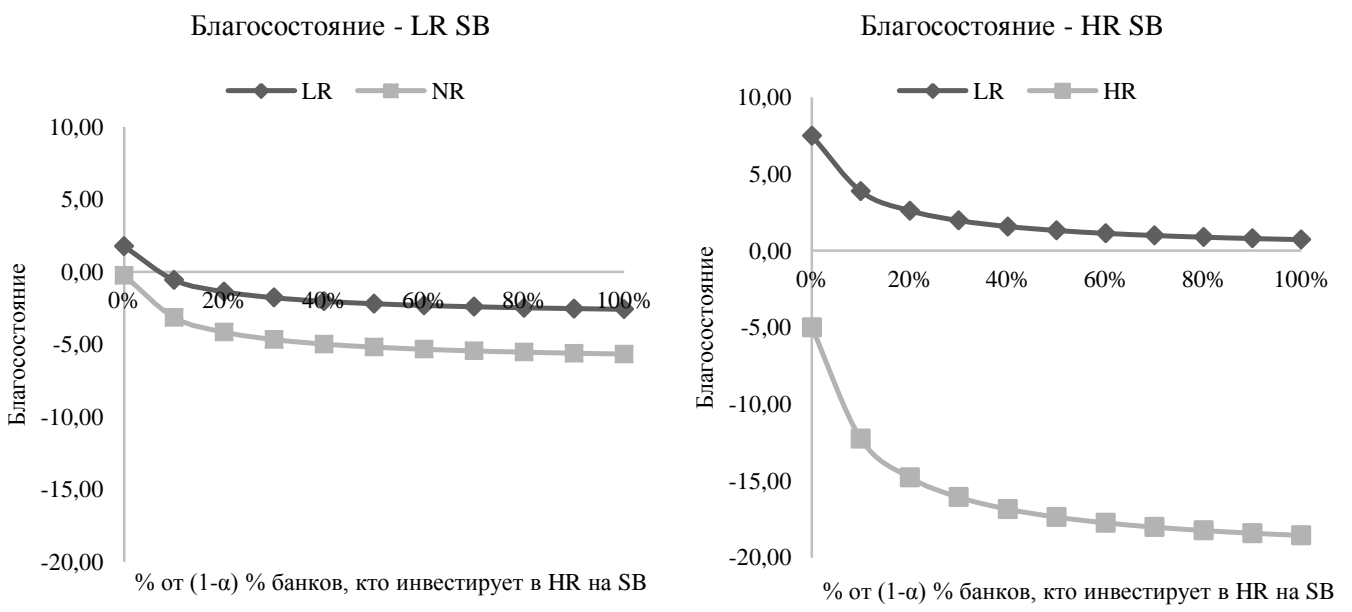

Рис. 6. Сравнение уровня благосостояния общества с учетом и без потерь инвесторов от участия банков во вложениях при двух видах банкинга

Параметры для графика: $\gamma(\mathrm{LR}-\mathrm{TB})=90 \% ; \gamma(\mathrm{HR}-\mathrm{SB})=50 \%$; $\mathrm{CAR}=30 \%, \alpha=40 \%, \mathrm{R}(\mathrm{NR}-\mathrm{TB})=1.3$, $\mathrm{R}(\mathrm{LR}-\mathrm{TB})=1.5, \mathrm{R}(\mathrm{HR}-\mathrm{SB})=2.0$

Источник: составлено автором 
Исходные параметры

\begin{tabular}{|c|c|c|c|c|}
\hline Актив & Банкинг & $\begin{array}{c}\text { Ожидаемые } \\
\text { потери, EL }\end{array}$ & $\begin{array}{c}\text { Процент по } \\
\text { кредиту, R_L }\end{array}$ & $\begin{array}{c}\text { Коэффициент } \\
\text { риска, RW }\end{array}$ \\
\hline LR & TB & 0.20 & 2.00 & 0.90 \\
\hline NR & TB & 0.10 & 1.50 & 0.50 \\
\hline LR & SB & 0.20 & 2.00 & - \\
\hline HR & SB & 0.50 & 2.50 & - \\
\hline
\end{tabular}

Источник: составлено автором

Перед началом анализа отметим, что показанные далее числовые выводы приведены не с целью создать бенчмарк, но показать на числовом (более простом) примере, что возможны ситуации, которые противоречат выводам [1]. Иначе говоря, что существуют случаи, когда традиционный банкинг приносит выше уровень благосостояния чем теневая даже при наличии регулирования капитала. То есть возможно найти такое значение CAR, при котором прибыль банков в традиционном банкинге все еще выше, чем в теневом.

При формировании ставки вариантом 1. Воздействие CAR на NR активы меньше чем на LR из-за более низкого риск-веса. Если бы в экономике был неограниченный объем NR и LR активов, то все средства $(\operatorname{Inv}+k)$ можно было бы вложить в NR активы при CAR $=18.18 \%$, в LR активы - при CAR $=10.10 \%$. CAR выше заданных значений приводит к ограничению инвестирования (возможно инвестировать, только определенную долю от $\operatorname{Inv}+k$, где доля рассчитывается как $k /((\operatorname{Inv}+k) * R W * C A R))$.

B рассматриваемой модели объем LR активов в экономике ограничен (в нашем примере только 40\% банков имеют к ним доступ, или каждый банк может инвестировать не более $40 \%$ средств при равномерном распределении доступа). Следовательно, для LR активов можно найти такой CAR, который ограничивает вложения до 40\%. Этот уровень CAR составляет $25.25 \%$.

На рис. 7 показано, что традиционный банкинг прибыльней и привлекательней для банков до CAR $=34 \%$. При CAR выше $34 \%$ для инвестирования в LR активы банки будут переходить на теневой банкинг. На рис. 8 показано, что если прибыль банков считать за вычетом потерь вкладчиков, то традиционный банкинг приносит при CAR до 100\% благосостояние обществу всегда выше.

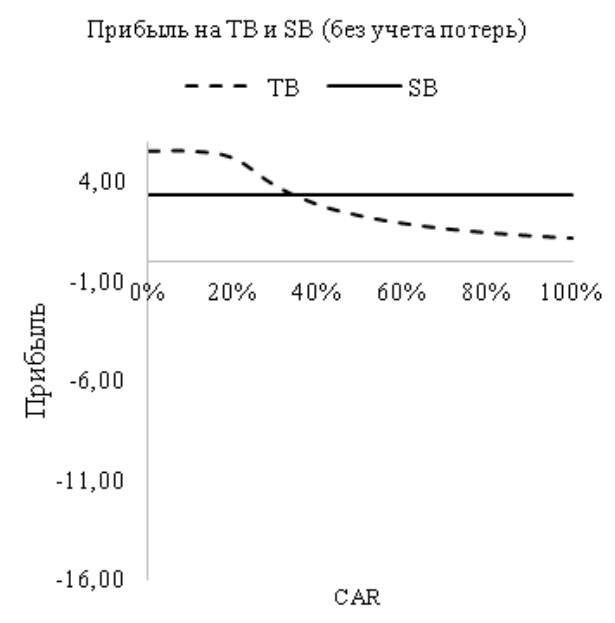

Puc. 7. Благосостояние в размере прибыли банков без учета потерь вкладчиков Источник: составлено автором 


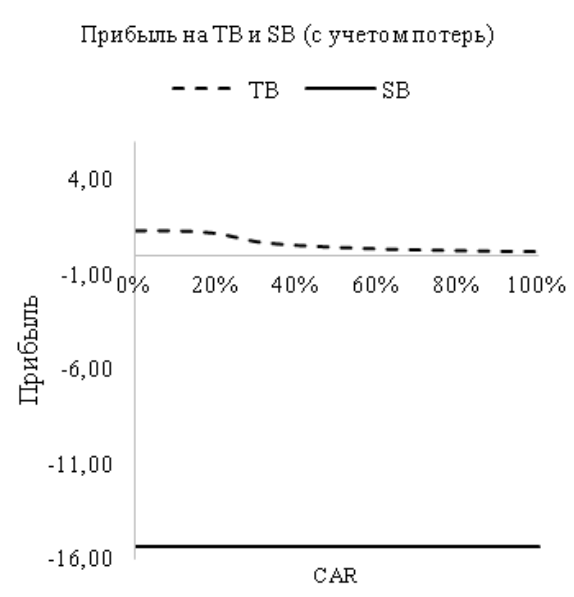

Puc. 8. Благосостояние в размере прибыли банков при учете потерь вкладчиков Источник: составлено автором

Можно сказать, что рисунки выше представляют два взгляда на систему: взгляд банка (рис. 7) и регулятора (рис. 8). При высоких потерях в теневом банкинге регулятор не может принять решение оставлять теневой банкинг (не проводить надзор банковской системы с целью выявления таких банков), так как видит существенное влияние этого типа банкинга на благосостояние общества. Таким образом, вывод [1] о том, что теневой банкинг следует оставить, так как он приносит выше благосостояние, оказывается неверным.

При формировании ставки вариантом 2. Как обсуждалось ранее, вариант 2 формирования ставки отражают большую неосведомленность инвесторов о вложениях банков. Такое формирование ставки, при котором все банки разделены на применяющие и не применяющие ПВР, может являться более реалистичным. Большая неосведомленность инвесторов ведет к тому, что ставки по методу 2 по сравнению с методом 1 для NR активов выше, для HR активов - меньше.

Напомним, что банки, не имеющие доступа к LR активам, выбирают между NR и HR активам. Поэтому чем больше вложений в HR активы в теневом банкинге, тем меньше вложений в NR активы в традиционном секторе, и тем выше ставка, назначаемая банкам, не применяющим ПВР. Поэтому с увеличением доли HR в теневом банкинге падает прибыль безрисковых активов.

Из рис. 9 видно, что прибыль в теневом банкинге оказывается выше. Процент инвесторам выплачивается с суммы инвестиций за вычетом ожидаемых потерь. Поскольку в традиционном банкинге ожидаемые потери меньше, то процент инвесторам платится с большей базы. В то же время в теневом банкинге из-за высоких потерь выплаты инвесторам ниже. Однако если расчет благосостояние будет сделан исходя из полученной прибыли за вычетом издержек (рис. 10), то увидим, что благосостояние в традиционном банкинге всегда выше благосостояния общества в теневом.

\section{Обсуждение расчета благосостояния с учетом риска}

В модели учтены ожидаемые потери в расчете прибыли, но не учтены непредвиденные потери, которые могут возникать вследствие усиления экономических шоков. Поскольку влияние шока может оказать более сильное влияние на HR активы (так как они обладают повышенным риском), то прибыль, взвешенная на риск-вес (мера непредвиденных потерь), окажется выше для традиционного банкинга несмотря на то, что без взвешивания мы видим иной результат: прибыль теневого банкинга выше. 


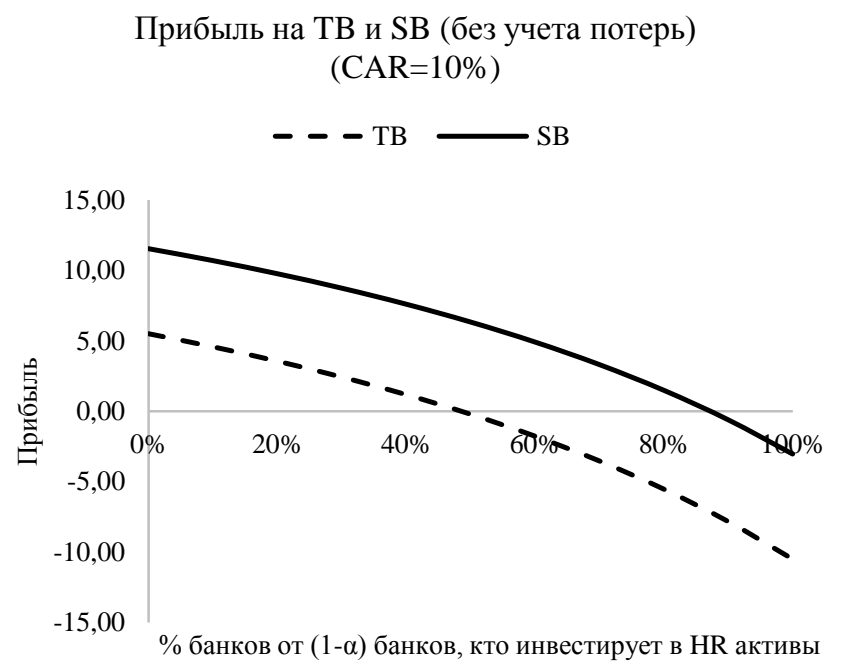

Puc. 9. Благосостояние в размере прибыли банков без учета потерь вкладчиков Источник: составлено автором

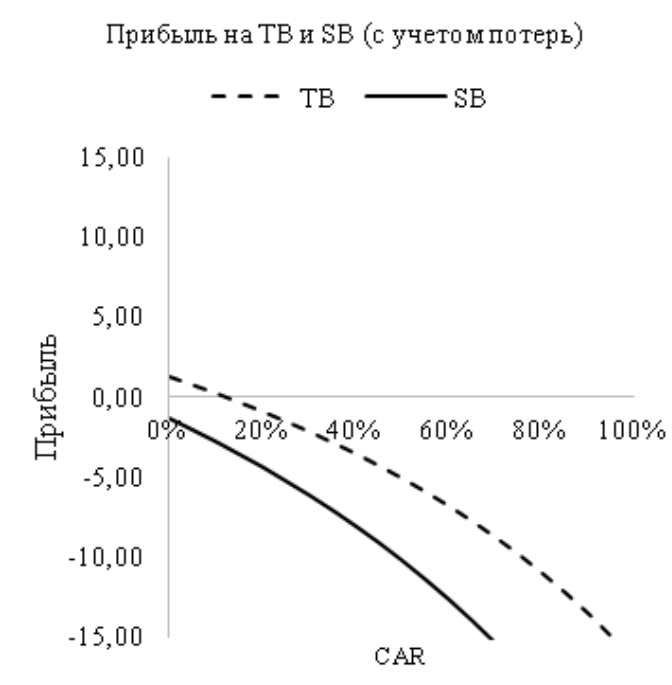

Puc. 10. Благосостояние в размере прибыли банков при учете потерь вкладчиков Источник: составлено автором

Ниже приведены рисунки, где изображены возможные варианты соотношения прибылей в традиционном и теневом банкинге, а также расчеты на основе калькулятора модели, предложенной в данной статье.

Взвешивание прибыли на риск-вес является упрощенным способом показать влияние макроэкономического шока на банки с разным уровнем риска вложений. Рассмотрим числовой пример.

На первом графике рис. 11 видно, что желтая линия с квадратным маркером, отражающая прибыль от HR активов в теневом банкинге выше прибыли от безрисковых и низкорискованных активов. Однако если в прибыли учесть непредвиденные потери путем взвешивания прибыли на риск-вес, то порядок альтернатив поменяется. Банки, которые вкладываются в безрисковые активы, при возникновении шока наивысший уровень прибыли. 


\section{До взвешивания на RW}

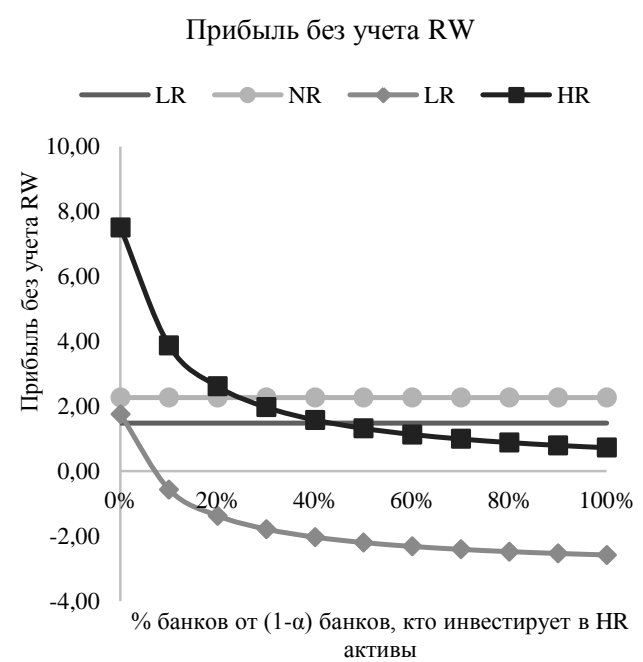

\section{После взвешивания на RW}

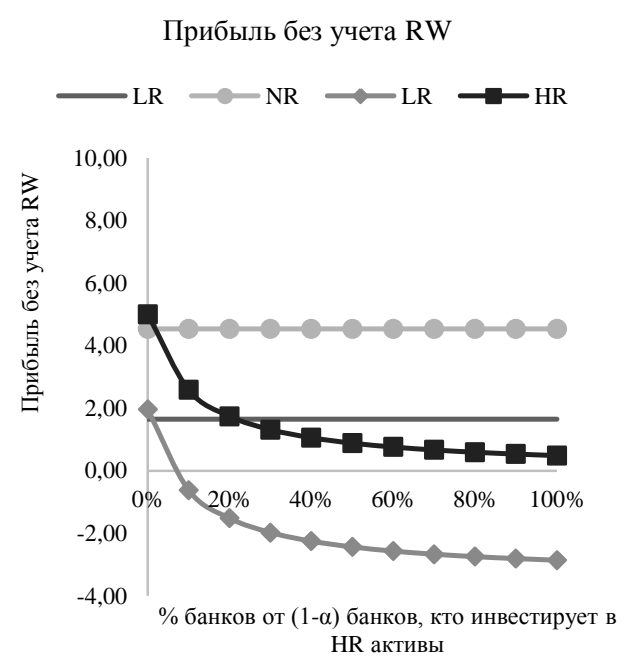

Puc. 11. Сравнение уровня прибыли со взвешиванием и без на риск непредвиденных потерь

Параметры для графика: $\gamma(\mathrm{LR}-\mathrm{TB})=90 \% ; \gamma(\mathrm{HR}-\mathrm{SB})=50 \% ; \mathrm{CAR}=30 \%, \alpha=40 \%, \mathrm{R}(\mathrm{NR}-\mathrm{TB})=1.3$, $\mathrm{R}(\mathrm{LR}-\mathrm{TB})=1.5, \mathrm{R}(\mathrm{HR}-\mathrm{SB})=2.0$

Источник: составлено автором

\section{Выводы}

Ordoñez G. [1] показал, что запрет теневого банкинга не выгоден для общества, так как прибыль, получаемая в теневом банкинге увеличивает благосостояние общества. В настоящей статье данный вывод опровергнут и показано, что существуют случаи, когда традиционный банкинг для банков выгоден даже при наличии регулирования капитала.

В работе в модель [1] были добавлены режим ПВР для банков, регулирование капитала, учет потерь вкладчиков и взвешивание прибыли на риск непредвиденных потерь. Это было сделано с целью проверить, остается ли устойчивым вывод о положительном влиянии прибыли в теневом банкинге на благосостояние общества.

Получено, что режим ПВР позволяет достичь первого наилучшего решения по [1]. Однако first-best действует при $C A R<\overline{C A R}$. В этом случае банки инвестируют в NR и LR активы в традиционном банкинге. При усилении регулирования $(C A R>\overline{C A R})$ first-best перетекает в случай, когда на ряду с традиционной системой действует и теневая. Поскольку ПВР позволяет инвестировать в LR активы в рамках традиционного банкинга, и first-best обладает наиболее высоким уровнем благосостояния, то получается, что случай, когда действует только традиционный сектор, приносит благосостояния больше, чем теневой. При этом CAR хотя и ограничивает вложения в активы в традиционном банкинге, но уменьшает объем ожидаемых потерь. Вывод о негативном влиянии высоких требований к капиталу совпадают с выводом [4], и не подтверждают вывод [5].

В исследовании показано, что благосостояние корректнее считать как прибыль за вычетом потерь вкладчиков. В этом случае, даже если прибыль в теневом банкинге выше, чем на традиционном, потери вкладчиков настолько высоки, что не покрывают выигрыш, полученный в теневом банкинге. Таким образом, для регулятора предложение [1] оставить теневой банкинг не может быть принято. 


\section{Список источников / References}

1. Ordoñez G. Sustainable Shadow Banking. American Economic Journal: Macroeconomics, 2018, vol. 10, no. 1, pp. 33-56. DOI: 10.1257/mac.20150346.

2. Financial Stability Board. Global Shadow Banking Monitoring Report 2019, 2020. Available at: https://www.fsb.org/wp-content/uploads/P190120.pdf (accessed 23.12.2020).

3. Пеникас Г.И. Проектирование оптимальной системы финансового регулирования рисков: опыт регулирования дорожного движения (Часть 1). Управление финансовыми рисками, 2016, №48 (4), сc. 242-254. [Penikas G.I. Proektirovanie optimal'noi sistemy finansovogo regulirovaniya riskov: opyt regulirovaniya dorozhnogo dvizheniya (Chast' 1) [Designing an optimal financial risk management system: road traffic management experience (Part 1)]. Upravlenie finansovymi riskami, 2016, vol. 48, no. 4, pp. 242-254].

4. Buchak G., Matvos G., Piskorski T., Seru A. Beyond the balance sheet model of banking: implications for bank regulation and monetary policy. National Bureau of Economic Research (NBER), 2020, Working Paper № 25149. Available at: https://www.nber.org/papers/w25149 (accessed 23.12.2020).

5. Mishin A. Dynamic Bank Capital Regulation and Optimal Macroprudential Policies in the Presence of Shadow Banks. Job Market Paper, 2020. Available at: https://c722622c-dda44fcf-9af5-c82f7cb1076a.filesusr.com/ugd/f22857_3c3dad4e108a46d899c75b93130b3c43.pdf (accessed 23.12.2020).

6. BCBS-bcbs128. Basel II: International Convergence of Capital Measurement and Capital Standards: A Revised Framework - Comprehensive Version, 2006. Available at: https://www.bis.org/publ/bcbs128.htm (accessed 23.12.2020).

7. BCBS-d424. Basel III: Finalising post-crisis reforms, December 2017. Available at: https://www.bis.org/bcbs/publ/d424.pdf (accessed 23.12.2020).

\section{Сведения об авторе / About author}

Ермолова Мария Дмитриевна, аспирант Департамента прикладной экономики Факультета экономических наук; стажер-исследователь Международного центра анализа и выбора решений НИУ ВШЭ. 109028 Россия, г. Москва, Покровский б-р, д.11. ORCID ID: 0000-0002-4617-1070. E-mail: MErmolova@hse.ru

Maria D. Ermolova, Postgraduate Student, Faculty of Economic Sciences, Department of Applied Economics; Research Assistant of International Centre of Decision Choice and Analysis NRU HSE. National Research University Higher School of Economics, 11, Pokrovsky blv., Moscow, Russia 109018. ORCID ID: 0000-0002-4617-1070. E-mail: MErmolova@hse.ru 